\title{
Lipid Peroxidation In Cerebral Malaria And Role Of Antioxidants
}

\author{
Adil Raza ${ }^{1}$, Sumit Kumar Varshney ${ }^{1}$, M. Shahid ${ }^{1}$, \\ Haris M. Khan ${ }^{1}$, M. Ashraf Malik ${ }^{2}$, Abbas A. Mahdi ${ }^{3}$ \\ F. Shujatullah ${ }^{1}$ \\ 1,Department Of Microbiology, 2,Paediatrics, J.N. Medical College \& Hospital, AMU, Aligarh-202002, UP, \\ India. \\ 3,Department Of Biochemistry, King George Medical University, Lucknow, UP, India.
}

\begin{abstract}
Malaria is one of the most important vector borne disease caused by the different species of a Plasmodium. Plasmodium falciparum causes complicated malaria. One of the important complications is cerebral malaria. This study was designed to estimate lipid peroxidation in the form of a metabolite malondialdehyde (MDA) in relation to parasitemia in cases of cerebral malaria. MDA in the serum of patients and that of healthy controls were estimated by the methods as given by Ohkhwa et al 1979. Mean MDA level in the controls was $1.14 \pm 0.20 \mathrm{n} \mathrm{mole} / \mathrm{ml}(\mathrm{N}=50)$, and mean MDA level in the cases was $3.03 \pm 0.84 \mathrm{n} \mathrm{mole} / \mathrm{ml}$ $(N=200)$. Which was significantly higher as compared to the controls $(P<0.05)$. Pearson coefficient of corelation between MDA level and parasitemia was +0.425 which shows strong positivity. There is higher lipid peroxidation in cerebral malaria because of release of reactive oxygen species (ROS) from the infected RBCs and from the immunocompetent cells. MDA level increases as parasitemia increases.
\end{abstract}

Keywords: Plasmodium falciparum, cerebral malaria, ROS, MDA

\section{Introduction}

Malaria is one of the most important parasitic infections in people all around the Globe, accounting for an approximately 500 million clinical attacks worldwide and more than 1 million causalities per year, mostly in Sub- Saharan Africa ${ }^{1}$. In India there were 1.49 million cases and 767 deaths due to malaria in the year $2010^{2}$. Malaria is associated with seasonally warm semi-arid areas where nearly 124 million people are considered at risk of climate-related malaria ${ }^{3}$. Most cases of malaria in India occur in Orissa. Orissa has a population of 36.7 million (3.5\% of India), and surprisingly it contributes $25 \%$ of a total of 1.5-2.0 million reported malaria cases annually, $39.5 \%$ of Plasmodium falciparum malaria, and $30 \%$ of deaths caused by malaria in India. Uttar Pradesh (UP), India's largest state, contributes only 5\% of total cases ${ }^{4}$. Cerebral malaria is one of the complications of the malaria caused by $P$. falciparum with clinical signs and symptoms of high grade fever, drowsiness, unarousable coma, seizures and sometimes psychotic behaviour ${ }^{5}$. Falciparum infected human RBCs are under constant oxidative stress ${ }^{6,7}$ because $P$. falciparum generates reactive oxygen species (ROS) within erythrocytes infected and also from immune activation ${ }^{8}$. These ROS damages erythrocytes in the form of lipid peroxidation producing metabolite malonyldialdehyde (MDA). It is important to know that armoury of erythrocytes consists of several antioxidant enzymes to protect them from $\operatorname{ROS}^{9}$. Therefore, the present study was designed to analyze the serum MDA concentration in $P$. falciparum infected patients with cerebral manifestations, and to analyze the relation of serum MDA concentration with $P$. falciparum parasitemia.

\section{1: Study population}

\section{Materials and methods}

The study was conducted in confirmed patients of $P$. falciparum infection with clinically proven cases of cerebral malaria, who attended out-patient clinics or those admitted to the wards of J N Medical College and Hospital, AMU, Aligarh, India, during May 2007 to September 2010. The study population was comprised of 200 children with the age range of two to five years. Fifty age and sex matched, population-based healthy volunteers were also included as controls. There were no clinical and laboratory signs and symptoms of falciparum malaria. 


\section{2: Serum samples}

This study was approved by the institutional ethical committee of the Jawaharlal Nehru Medical College and Hospital, AMU. , Aligarh UP, India. Blood specimens were obtained from the patients and healthy volunteers after taking informed consent. Venous blood was collected aseptically from the patients and was kept in a dark environment before centrifugation. Serum was obtained by centrifugation at $1,500 \times \mathrm{g}$ for 5 minutes at room temperature, and aliquots were prepared and immediately stored at $-70^{\circ} \mathrm{C}$ until processed further. Estimation of lipid peroxidation was done in terms of malondialdehyde (MDA) by the method described by Ohkhwa ${ }^{10}$ et al 1979 spectro-photometrically. Thick and thin Giemsa-stained blood films were screened for the presence of Plasmodium species. The parasite count (parasites $/ \mu \mathrm{L}$ ) was done by counting 200 white blood cells and the number expressed on the basis of $8,000 \mathrm{WBC} / \mu \mathrm{L}^{11,12}$.

\section{3: Calculation of parasitemia:}

$$
\text { Number of parasite per } \mu \mathrm{L}=\frac{\text { WUDEER OF PARASITES SEEN }}{\text { MUNDER OFLEUKOCYIES SEEN }} \times 8000
$$

\section{4: Statistical analysis:}

Statistical analysis was done using SPSS, version 17, Statistics software. Unpaired Student's t was applied for the comparison of serum MDA. Descriptive statistics including mean and SDs were calculated for each continuous variable. Pearson correlation analyses were performed to determine the degree and direction of association between two variables (parasitemia and serum MDA concentration). The $\mathrm{P}<0.05$ was considered as significant.

\section{Results and discussion}

As observed in the table 1 mean \pm SD of serum MDA in the cases is $3.02 \pm 0.84 \mathrm{n}$ mole $/ \mathrm{ml}(\mathrm{N}=200)$. The mean $\pm \mathrm{SD}$ of the fifty age and sex matched healthy controls was $1.14 \pm 0.20 \mathrm{n}$ mole/ml, which is significantly lower than the mean \pm SD of cases $(3.02 \pm 0.84 \mathrm{n}$ mole $/ \mathrm{ml})$. From table -1 and figure- 1 it is obvious that serum MDA level was increased as the parasitemia increases. Unpaired Student's t test was put for comparison of MDA level of cases and MDA level of age and sex matched healthy controls. P value was found to be $<0.05$, which is statistically significant. Also Mann-Whitney rank sum test was put with Mann-Whitney U Statistic value 17.50 and $\mathrm{T}$ value 1292.50 and $\mathrm{P}$ value $<=0.05$.It is obvious from table- 1 and figure- 1 that as the parasitemia increases the serum MDA level of the affected subject's increases. Also in co-relation analysis, $r=$ $+0.425, \mathrm{P}<0.05$, which of shows strong positivity of serum MDA level against parasitemia. Haem part of haemoglobin is a vital factor for a diverse set of proteins involved in various physiological functions such as respiration, oxygen transport and drug detoxification. The accumulation of free haem has deleterious effects on the normal physiology. Haem has capacity to combine lipid bilayers. It also catalyses lipid peroxidation, inhibit various enzymatic activity, lyses cells and parasites ${ }^{13,14}$. Falciparum infected human RBCs are under constant oxidative stress ${ }^{6,7}$ because $P$. falciparum generates reactive oxygen species (ROS) within erythrocytes infected and also from immune activation ${ }^{8}$. These ROS damages erythrocytes in the form of lipid peroxidation producing metabolite malonyldialdehyde (MDA). ROS also damage DNA, activate procarcinogens, initiate lipid peroxidation, inactivate enzyme systems and alter the cellular antioxidants defence system ${ }^{15}$. It is important to know that armoury of erythrocytes consists of several antioxidant enzymes to protect them from ROS ${ }^{9}$. Plasma ascorbate plays important role in protecting plasma lipids from reactive oxygen species attack due to malaria infection, however ascorbate is rapidly oxidised when challenged by oxidants released from activated polymorphs due to malaria infection ${ }^{16}$. Ascorbic acid level was significantly reduced by malaria infection $17,18,19,20,21$ and this coincided with enhanced level of MDA. Once ascorbic acid has been used up there is initiation of lipid peroxidation ${ }^{22}$. Also there is decrease in the level of plasma Vitamin $\mathrm{E}^{20}$ and vitamin $\mathrm{A}^{4}$ during malaria infection. Beneficial protective effects of retinol or zinc on malaria-related morbidity have been documented in Papua New Guinea, Peru and Zanzabari ${ }^{23,24,25}$.In our study there is gradual increase in serum MDA level as the parasitemia increases. Recently D'douza et al 2009 also found the increment in the serum MDA level ${ }^{26}$. Severe malaria infection causes activation of neutrophils and monocytes resulting increase in cytokine level and endothelial damage. It is experimentally proved that neutrophils are activated by product of malaria parasites ${ }^{27}$ and also other inflammatory products viz cytokines produced in malaria infections ${ }^{28,29,30}$.

\section{Conclusions}

From these studies it can be concluded that the substantial increase in lipid peroxides in malaria patients might be the result of reactive oxygen species production, by the activated immune system, by the parasite itself and blood phagocytes. Administration of antioxidant Vitamins C, vitamin E, and Vitamin A along with antimalarial treatment may be fruitful to avoid malarial anaemia due to excessive haemolysis, morbidity and mortality due to malaria. 
Table -1

\begin{tabular}{|l|l|l|}
\hline Parasitemia per $\mu \mathrm{L}$ & MDA, Mean \pm SD & $\mathrm{n}$ \\
\hline $600-800$ & & \\
\hline $801-1000$ & $1.58722 \pm 0.12447$ & 18 \\
\hline $1001-1200$ & $2.06185 \pm 0.16427$ & 27 \\
\hline $1201-1400$ & $2.53233 \pm 0.07564$ & 30 \\
\hline $1401-1600$ & $2.83 \pm 0.08679$ & 28 \\
\hline $1601-1800$ & $3.2319 \pm 0.14159$ & 26 \\
\hline $1801-2000$ & $3.69931 \pm 0.12271$ & 29 \\
\hline $2001-2200$ & $4.0335 \pm 0.069$ & 20 \\
\hline & $4.28773 \pm 0.09666$ & 22 \\
\hline & $3.0288 \pm 0.84729$ & $\mathrm{~N}=200$ \\
\hline
\end{tabular}

Table-2

\begin{tabular}{|l|l|c|l|l|l|}
\hline Group & $\mathrm{N}$ & Missing & Median & $25 \%$ & $75 \%$ \\
\hline MDA control & 50 & 0 & 1.080 & 0.990 & 1.320 \\
\hline MDA Cases & 200 & 0 & 2.935 & 2.442 & 3.808 \\
\hline
\end{tabular}

Mann-Whitney Rank Sum Test

Fig-1

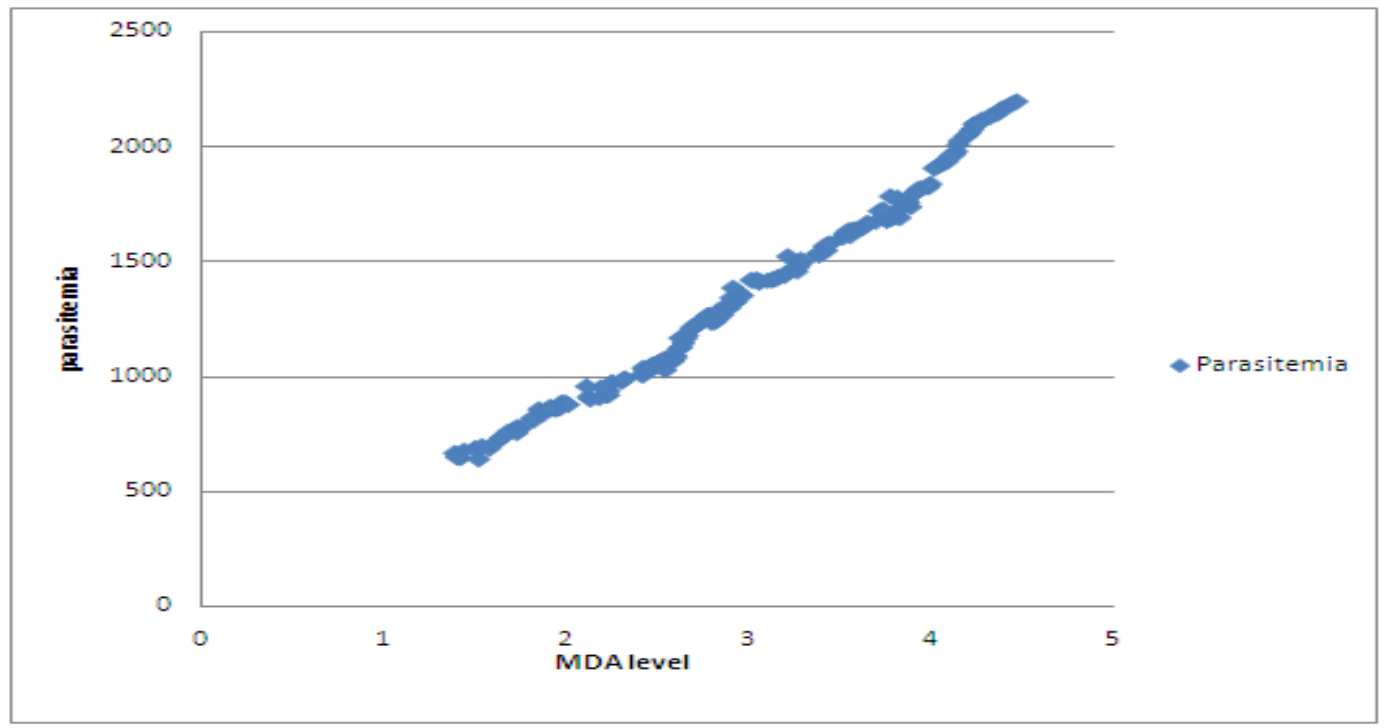

References:

[1]. B.M. Greenwood, K. Bojang, C. Whitty, G.A.T. Targett, Malaria, Lancet,2005,365, 1487-1498.

[2]. H. M. Khan, F. Shujatullah, A. Raza, A. Akhtar, S. Gupta, Seasonal variations in vector borne infections-malaria and dengue, Journal of pure and applied microbiology, 2012, 6(spl edn),59-62.

[3]. E. Worrall, A. Rietveld, C. Delacollette, The burden of malaria epidemics and cost-effectiveness of interventions in epidemic situations in Africa, Am. J. Trop. Med. Hyg,2004, 71 (Suppl. 2), 136-140.

[4]. A. Raza, H.M. Khan, M.A. Malik, A.A. Mahdi, M. Shahid, F. Shujatullah, Serum retinol concentration in patients with acute falciparum malaria in Aligarh, India, J Infect Dev Ctries, 2009, 3(11),865-868.

[5]. A. M. DONDORP, Pathophysiology, clinical presentation and treatment of cerebral malaria, Neurology Asia, $2005,10,67-77$.

[6]. J. Eaton , J. R. Eckman , E. Berger, H.S. Jacob, Suppression of malaria infection by oxidant- sensitive host erythrocytes, Nature, 1976, 264, 758-760.

[7]. J. Golenser, E. Marva , M. Chevion, The survival of plasmodium under oxidant stress, Parasitology Today, 1991, 7, $142-146$.

[8]. R. N. Rath, N. Panigrahi, B.K. Das, P. K. Das, Lipid peroxidation in acute falciparum malaria, Ind J Med Res 1991, 93, $303-305$.

[9]. M. Amy, M. Gelasius , U.S. Anuraj, N. Grace, M. George, D.S. Richard, Antioxidant status and acute malaria in children in Kampala Uganda, Am J Trop Med Hyg 2001, 65,115-119. 
[10]. H. Ohkawa, N. Ohishi, K. Yagi, Assay for lipid peroxides in animal tissues by thiobarbituric acid reaction, Anal Biochem, 1979, 95, 351-358.

[11]. J. F. Trape, (1985) Rapid evaluation of malaria parasite density and standardization of thick smear examination for epidemiological investigations, Trans R Soc Troop Med Hyg, 1985, 79: 181-184.

[12]. WHO. Basic laboratory methods in medical parasitology (1991) Special techniques for plasmodia. WHO Geneva pp. 48.

[13]. T. H. Schmitt, A. Wilson, J. Frezzatti, S. Schreier : Hemin-induced lipid membrane disorder and increased permeability: a molecular model for the mechanism of cell lysis, Arch Biochem Biophys, 1993, 307,96-103.

[14]. I. Y. Gluzman, S. E. Francis, A. Oksman, C.E.Smith, K.L. Duffin, D.E. Goldberg, Order and specificity of the Plasmodium falciparum haemoglobin degradation pathway, J Clin Invest 1994, 93,1602-1608.

[15]. Y. Sun, Free radicals, antioxidant enzymes and carcinogenesis, Free Rad Biol Med 1990, 8,583-899.

[16]. B. Frei, R. Stocker, M.N. Ames, (1988). Antioxidant defenses and lipid peroxidation in human blood plasma. Proceedings of the National Academy of Sciences, (USA), 1988, 85, 9748 - 9752.

[17]. O. U. Njoku, I. C. Ononogbu, D. E. Nwachukwu, Plasma cholesterol, B-carotene and ascorbic acid changes in human malaria, J Commun Dis 1995, 27 (3), 186-190.

[18]. G.K. Isamah, S.O. Asagba, The effect of Plasmodium falciparum infection on the levels of malondialdehyde [MDA] and ascorbic acid on Nigerian children, J, App. Sci. Environmental Management 2003, 7 (2), 59-61.

[19]. A.O. Egwunyenga, G. Isamah, O.P. Nmorsi, Lipid peroxidation and ascorbic acid levels in Nigeria children with acute falciparum malaria, Afr J Biotech 2004, 3 (10),560-563.

[20]. Prasannachandra, Vivian D'Souza and Benedicta D'Souza. Comparative study on lipid peroxidation and antioxidant vitamins E and C In falciparum and vivax malaria, Indian Journal of Clinical Biochemistry, 2006,21 (2), 103-106

[21]. A. Raza, H. M. Khan, F. Shujatullah, T. Tripathi, M. A. Malik, M. Shahid, A. A. Mahdi, Evaluation of serum ascorbic acid levels in acute falciparum malaria, Biomedical Research, 2010, 21(4),397-400

[22]. B. Frei, Reactive Oxygen species and antioxidant vitamins: Mechanisms of action. The American J. Med, 1994, $97,34-55$.

[23]. A. H. Shankar, B. Genton, R.D. Semba, M. Baisor, J. Paino, S.Tamja , T. Adiguma, W. L. Rare, D. Bannon, J.M. Tielsch, K.P. West Jr, M. P. Alpers, The influence of zinc supplementation on morbidity due to Plasmodium falciparum: a randomised trial in preschool children in Papua New Guinea, 2000, Am J Troop Med Hyg, 62, 663-669.

[24]. S. E. Cusick, J.M. Tielsch, M. Ramsan, J.K. Jape, S. Sazawal, R.E. Black, R.J. Stoltzfus, Short term effects of vitamin A and antimalarial treatment on erythropoiesis in severely anemic Zanzibari preschool children, 2005, Am J Clin Nutr, 82, 406-412

[25]. S.A. Richard, N. Zavaleta, L.E. Caulifield, R.E. Black, R.S. Witzig, A. H. Shankar, Zinc and iron supplementation and malaria, diarrhoea, and respiratory infections in children in the Peruvian Amezon, Am J Troop Med Hyg, 2006, 75: 126-132.

[26]. B. D'Souza, V. D'Souza, H. Swagata, K. Vijayalaxmi, A. S. Namratha, Erythrocyte antioxidant enzymes and their correlation with malon-dialdehyde in malaria, Biomedical Research 2009, 20 (1), 25-27.

[27]. A. Kharazmi, S. Jepsen, B. J. Andersen, Generation of reactive oxygen radicals by human phagocytic cells activated by Plasmodium falciparum, Scand. J. Immunol, 1987, 25,335-341.

[28]. M. R. Shalaby, B. B. Aggarwal, E. Rinderknecht, L. P. Svedersky, B. S. Finkle, M. A. Palladino, Jr, Activation of human polymorphonuclear neutrophil functions by interferon-gamma and tumor necrosis factors, J. Immunol. 1985, 135,2069-2073.

[29]. M.R. Shalaby, M. A. Palladino Jr, S. E. Hirabayashi, T. E. Eessalu, G. D. Lewis, H. M. Shepard, B.B. Aggarwal, Receptor binding and activation of polymorphonuclear neutrophils by tumor necrosis factor-alpha, J. Leukoc. Biol, 1987, 41,196-204.

[30]. W. F. Westlin, and M. A. Gimbrone, Jr. Neutrophil-mediated damage to human vascular endothelium. Role of cytokine activation, Am. J. Pathol, 1993, 142,117-128. 